If stock owners, keepers and producers are to maintain viable herds and flocks in an environment that is gradually changing as a result of climatic and other factors, they need to be aware of the traits that have enabled these animals to survive against such odds so that they can capitalise on these in sustainable livestock farming systems.

Rising costs of stock remedies and feeds - as well as a growing demand for a more healthy and safe product have also stimulated interest in adapted breeds that can survive and produce without excessive additives and stimulants and this has led to renewed interest in breeds that can either be used as purebreds - or as part of a combination/ composite capable of producing in a specific biome.

Sustainable and economically efficient red meat production is totally dependent on the number of saleable animals produced per unit area - and this is totally dependent on fertility that is in turn influenced by stressors such as temperature and humidity, the quality of the available grazing, availability of water and biting and sucking insects.

Cattle in the tropics and sub tropics need to be heat and insect tolerant, able to walk long distances, browse and graze and to offset any stressors that may influence intake, digestion and reproduction.

Heat tolerant animals have slightly different skeletal structures so that less area is exposed to direct heat rays and this also influences the angle of the rib cage which, in turn influences the ability to cool the blood through evaporative cooling and an exchange of heat without excessive panting.

In addition, Sanga cattle have baggy sweat glands that promote evaporative cooling from a skin area that is enlarged by a number of folds.

Animals that are tick and fly repellent have sensitive pilo motor nervous systems. Insect contact causes well-developed paniculis muscles to 'shake' the hide and unsettle the insect and a longer tail with a flexible tip acts as a very efficient fly swatter.

The anatomy of the Sanga also makes it easier to dislodge ticks and other sucking insects by either scratching the affected parts of the body with the hind claws or even chewing certain areas such as the scrotum in bulls and the tip of the tail. Horned animals can reach certain fly strike areas that would be inaccessible if they were polled.

In addition to being non selective grazers and selective browsers, the teeth of Sanga cattle last longer than those of exotic breeds as the enamel tends to harden with age and this enables them to live longer and remain productive longer than less adapted breeds in the same environment.

The Sanga is therefore the ideal mother line to use in environments that are already hot - or are becoming hotter - and where vegetation is gradually changing from grassland into woodland. Owners and keepers of Sanga cattle should therefore capitalize on their adaptive traits to ensure that they can continue with sustainable production despite the changes brought about by global warming and biome shift.

Current and future production systems in Southern Africa should be based on breeds such as the Sanga - either are pure breeds or as mother lines for terminal crossing - or for the development of composites along the same lines as the Bonsmara, Hugenoot, Afrisim and Pinzyl.

\title{
Planning for climate change - developing a heat load model for dairy cows in the tropics and sub-tropics
}

\author{
John Gaughan $^{\dagger}$ \\ School of Animal Studies, The University of Queensland, Gatton 4343, Australia
}

\section{Introduction}

There is increasing global demand for cows' milk. Much of this demand is in developing countries e.g. Indonesia produced 1.2 million $L$ of milk day ${ }^{-1}$ in 2007, which was approximately $25 \%$ of its demand (FAS, 2007). Climate change (CC) models suggest an increase in the severity of extreme weather events, including an increase in the duration and intensity of heat waves. There is a need to plan now for climate change. The ability of farmers to adapt to CC will depend in part on how well the impacts of CC on livestock are understood. Currently the THI is used to predict the impact of climatic conditions on milk production (MP), fertility and dry matter intake (DMI). However THI does not account for wind speed (ws), solar radiation (sr), or the intensity and duration of a heat event. The current study was undertaken to develop a heat load model for dairy cows housed outside in tropical and sub-tropical environments.

\section{Animals and facilities}

The 121 day study was conducted at the University of Queensland dairy during Australian summer (December to March), with the approval of the University Animal Ethics Committee. Cows $(n=150)$ were housed in a feedlot (1.4 ha.) with occasional access to pasture. Shade was provided by an open sided shed with a steel roof $\left(1.6 \mathrm{~m}^{2} \mathrm{cow}^{-1}\right)$, a feed pad $\left(1.3 \mathrm{~m}^{2} \mathrm{cow}^{-1}\right)$ with a steel roof and an open sided shed with $90 \%$ solar block shade cloth $\left(1.8 \mathrm{~m}^{2} \mathrm{cow}^{-1}\right)$. Sprinklers in the holding yard provided cooling prior to milking. Cows were milked twice daily at

\footnotetext{
† E-mail: j.gaughan@uq.edu.au
} 
$0600 \mathrm{~h}$ and $1400 \mathrm{~h}$. Milking cups fitted with in line milk meters allowed individual MP to be recorded. Because the cows varied in terms of days (d) in milk (DIM) and MP capacity they were grouped (for statistical analysis) as follows: DIM category $1=<56 \mathrm{~d} ; 2=57$ to $100 \mathrm{~d}$; $3=101$ to $224 \mathrm{~d} ; 4=>224 \mathrm{~d}$; and MP categorised as; $1=<12 \mathrm{~kg} \mathrm{~d}^{-1} ; 2=12$ to $20 \mathrm{~kg} \mathrm{~d}^{-1} ; 3=20$ to $30 \mathrm{~kg} \mathrm{~d}^{-1} ; 4=>30 \mathrm{~kg} \mathrm{~d}^{-1}$. The cows were fed a mixed ration of $70 \%$ sorghum silage, $15 \%$ brewers grain, $10 \%$ corn cobs, and $5 \%$ concentrate. Pasture consisted of rye grass, forage sorghum, alfalfa, and native grasses. Water was provided via two troughs at the feedlot and a trough at the holding yard.

\section{Climatic conditions}

Climatic conditions were recorded at 10 min intervals using a weather station (Easidata MK 4, Environdata Australia P/L, Warwick, Australia) located $30 \mathrm{~m}$ from the cows. Climate variables recorded were ambient temperature $\left(\mathrm{T}_{\mathrm{A}} ;{ }^{\circ} \mathrm{C}\right)$, relative humidity $(\mathrm{rh} ; \%), \mathrm{Ws}\left(\mathrm{m} \mathrm{s}^{-1}\right), \mathrm{sr}^{\circ}\left(\mathrm{W} \mathrm{m}{ }^{-2}\right)$, and black globe temperature $\left(\mathrm{bg}^{\circ}{ }^{\circ} \mathrm{C}\right)$. The $\mathrm{THI}$ was calculated from $\mathrm{T}_{\mathrm{A}}$ and $\mathrm{rh}$. The mean $\mathrm{THI}\left(\mathrm{THI}_{\mathrm{M}}\right)$ between 1100 and $1600 \mathrm{~h}$ was calculated each day. $\mathrm{THI}_{\mathrm{M}}$ was then categorised as thermoneutral; $\mathrm{THI}_{\mathrm{M}}<72$; moderate; $\mathrm{THI}_{\mathrm{M}}>72<78$; hot; $\mathrm{THI}_{\mathrm{M}}>78<86$; and extreme; $\mathrm{THI}_{\mathrm{M}}>86$.

\section{Animal data}

The cows were observed 3 times $\mathrm{d}^{-1}(0800,1200$, and $1400 \mathrm{~h})$. Cow location (at feed, at water, under shade, in sun); posture (standing or lying); and panting score (PS) $(0=$ regular breathing, $4=$ open mouth, tongue out, excessive drooling) were recorded. Mean panting score (MPS) was then calculated on a herd to assess the severity of the heat stress (Gaughan et al., 2008). Vaginal temperature $\left(V_{T}\right)$ was recorded every 10 min for 5 days in 70 cows using data loggers (Hobo U22-001 Pro V2, Onset Computer Corporation, Bourne MA, USA).

\section{Statistical analysis}

Data were converted from animal numbers to proportion of the herd. Percentage of cows recorded for each PS was transformed to a normalised distribution using squared root arcsine transformation before being statistically analysed. The data were analysed using PROC GLM and PROC MIXED (SAS Inst. Inc., Cary, NC). MP and VT were analysed using repeated measures ANOVA. The model included the effects of the $\mathrm{THI}_{\mathrm{M}}$ categories, DIM category, MP category, month, time of day and day as fixed effects. The specific term for the repeated statement was cow within day. The transformed PS, and MPS were analysed using a repeated measures model which included day, time of day, month, $\mathrm{THI}_{\mathrm{M}}$ category DIM category, $\mathrm{V}_{\mathrm{T}}$ and MP category as fixed effects and cow as a random effect. The specified term for the repeated statement was day. The between month differences in the climatic variables were analysed using PROC GLM.

\section{Results}

Heat stress occurred on 106 of the 121 day study. Ambient temperature exceeded $30^{\circ} \mathrm{C}$ on $70 \mathrm{~d}, 35^{\circ} \mathrm{C}$ on $26 \mathrm{~d}$ and $40^{\circ} \mathrm{C}$ on $3 \mathrm{~d}$. Rainfall totalled $290 \mathrm{~mm}$. The THI was a good predictor of change in MP based on monthly weather data $\left(P<0.001 ; r^{2}=0.56\right)$. However, it was less so for individual day effects $\left(P<0.01 ; r^{2}=0.15\right)$, and $V_{T} ; V_{T}=37.34-0.021 \times$ THI $\left(r^{2}=0.26 ; P<0.001\right)$. When a number of weather variables were included a better model emerged for $V_{\mathrm{T}}$. If $\mathrm{sr}$ values $\leqslant 0$ were removed i.e. night time values, the model was $V_{\mathrm{T}}=$ $\left.36.11+(0.07 \times \mathrm{ws})+(0.01 \times \mathrm{rh})+\left(0.07 \times \mathrm{T}_{\mathrm{A}}\right)+0.008 \times \mathrm{bg}\right)-(0.0006 \times \mathrm{sr})\left(r^{2}=0.73 ; P<0.001\right)$. When low intensity sr $\leqslant 50$ was removed bg effects were not significant. The model was then; $V_{T}=35.28+(0.07 \times W S)+(0.02 \times r h)+\left(0.10 \times T_{A}\right)-(0.005 \times s r)$ $\left(r^{2}=0.72 ; P<0.001\right)$. Increasing $\mathrm{V}_{\mathrm{T}}$ was negatively correlated with daily MP $(P<0.001)$. The level of MP and DIM are important variables influencing $\mathrm{V}_{\mathrm{T}}(P<0.001)$ and will need to be included in a heat load model. These data suggest that the THI may not be a suitable tool for predicting the impact of CC on dairy cow production.

\section{Reference}

Gaughan JB, Mader TL, Holt SM and Lisle A 2008. A new heat load index for feedlot cattle. Journal of Animal Science 86, $226-234$. 